\title{
Sidewall slopes and roughness of SU-8 HARMST
}

K. D. Vora $\cdot$ B.-Y. Shew $\cdot$ B. Lochel $\cdot$

E. C. Harvey - J. P. Hayes - A. G. Peele

Published online: 30 May 2008

(C) Springer-Verlag 2008

\section{Erratum to: Microsyst Technol \\ DOI 10.1007/s00542-007-0506-y}

There is an error in the caption to Fig. 8 and the accompanying text. The reference to a $4 \mu \mathrm{m}$ opening should be read as $50 \mu \mathrm{m}$. Also in the caption to Fig. 8 the statement that "Diffraction at top of the resist is neglected as the mask and resist were in hard contact." should be ignored as diffraction was in fact included in the calculation.

The online version of the original article can be found under doi:10.1007/s00542-007-0506-y.

K. D. Vora · A. G. Peele $(\bowtie)$

Department of Physics, La Trobe University,

Bundoora 3086, Australia

e-mail: a.peele@latrobe.edu.au

B.-Y. Shew

Device Technology Group, National Synchrotron Radiation

Research Center, 101, Hsin-Ann Road,

Hsinchu SBI Park 30077, Taiwan

B. Lochel

Application Center for Micro Engineering, BESSY,

15 Albert-Einstein-Strasse, 12489 Berlin, Germany

E. C. Harvey · J. P. Hayes

Industrial Research Institute of Swinburne, Swinburne

University of Technology, 543-545 Burwood Road,

3122 Hawthorn, VIC, Australia 